\section{Open globe injuries: factors predictive of poor outcome}

\author{
Abstract \\ Objective Despite advances in ocular and \\ orbital imaging, instrumentation, materials, \\ and surgical procedures, the management of \\ open globe injuries continues to pose difficult \\ management dilemmas. In this retrospective \\ study, we identify clinical characteristics and \\ outcome of a series of open globe injuries \\ presenting to a major UK centre.
}

Method Operating department records were reviewed to identify all patients who had undergone repair of an open globe injury from 1 January 1998 to 1 January 2003 at the Manchester Royal Eye Hospital. Case notes were examined to determine demographic data, mechanisms of injury, influence of alcohol/drugs, and location of injury. The Snellen visual acuity on presentation and initial clinical signs were recorded.

Results In total, 115 cases of open globe injury were identified of which 107 cases notes were available for review. Injury to the eye with a sharp object accounted for 71/107 (66\%) cases and blunt mechanisms for 30/107 (28\%) cases. In six $(6 \%)$ cases the cause of injury was unknown. The rate of secondary enucleation in our series of 107 open globe injuries was 13/107 (12\%). Significant risk factors on

Manchester Royal Eye Hospital, Lister Centre, Manchester, UK

Correspondence: I Rahman, Manchester Royal Eye Hospital,

Lister Centre, Nelson Street, Manchester M13 9WL, UK Tel: +44161276 1234; Fax: + 441612726618 . E-mail: imran1973@ tiscali.co.uk

Received: 20 June 2005 Accepted: 4 August 2005 Published online: 23 September 2005

Interests, financial and other: None presentation associated with eventual enucleation included relative afferent pupillary defect $(P<0.001)$, absence of a red reflex $(P<0.001)$, presence of a lid laceration $(P<0.02)$, a blunt mechanism of injury $(P<0.02)$, and an initial VA worse than $6 / 60$ $(P=0.03)$.

Conclusion From this retrospective study, we have identified several factors that may aid the clinician in deciding on the prognostic value of primary repair. Blunt injuries associated with adnexal trauma, with poor initial visual acuity, the presence of an RAPD or retinal detachment, and the absence of a red reflex are associated with a significantly higher rate of subsequent enucleation. published online 23 September 2005
Eye (2006) 20, 1336-1341. doi:10.1038/sj.eye.6702099;
I Rahman, A Maino, D Devadason and

B Leatherbarrow

Keywords: prognostic factors; open globe injuries; enucleation; visual outcome; penetrating eye injuries

Introduction

Open globe injuries are a major cause of monocular blindness. In all, $90 \%$ or more of these open globe injuries are thought to be preventable. Trauma from violent behaviour accounts for a large proportion of open globe injuries. ${ }^{1-4}$ Highly populated urban areas account for the more common and serious injuries. ${ }^{5}$ Desai et $a l^{6}$ reported an incidence of 8.14 per 100000 population for ocular trauma in Scotland annually. A blinding outcome was described in 0.41 per 100000 population. In the USA, penetrating eye injury accounts for 3.81 injuries per 100000 annually. ${ }^{4}$ An Australian review cited an incidence of 3.6 per $100000 .^{7}$ Methods of reporting and definitions of ocular injury, however, may limit a direct comparison of such large studies.

The management of open globe injuries continues to pose difficult management dilemmas. The standard practice of ophthalmologists worldwide in these cases has been to undertake a primary surgical repair to restore the structural integrity of the globe at the earliest opportunity regardless of the extent of the injury and the presenting visual acuity. Despite microsurgical improvements in management in this devastating setting, ${ }^{8}$ there remain many eyes that cannot be salvaged. A primary enucleation is usually only considered in eyes that are beyond primary repair.

In this retrospective study, we identify clinical characteristics and outcome of a series of open globe injuries presenting to a major UK centre and discuss factors affecting long-term prognosis (Boxes 1 and 2).

\section{Method}

This retrospective study reviewed operating department records via a computerised 


\section{Box 1 Wound categorisation ${ }^{\mathrm{a}}$}

Full-thickness ocular wound limited to cornea

Full-thickness ocular wound extending to but not past the plane of rectus muscle insertion

Full-thickness ocular wound extending anterior to the equator Full-thickness ocular wound extending posterior to the equator

a Categories used adhered to the Birmingham Eye Trauma Terminology (BETT). ${ }^{9}$

Box 2 Definitions of ocular trauma

\begin{tabular}{ll}
\hline Penetration & $\begin{array}{l}\text { Full-thickness corneoscleral wound with no } \\
\text { exit wound } \\
\text { Full-thickness corneoscleral wound with an } \\
\text { exit wound }\end{array}$ \\
IOFB & Foreign object retained within the globe
\end{tabular}

database to identify all patients who had undergone repair of open globe injuries from 1 January 1998 to 1 January 2003 at the Manchester Royal Eye Hospital. Case notes were examined to determine the mechanisms of injury (sharp, blunt, projectile), influence of alcohol/ drugs, whether the injury was the result of an accident or an assault, and location of injury (home, work, school, indoors, outdoors). Demographic data retrieved included patient age and sex. Presenting Snellen visual acuity and initial clinical signs (hyphaema, cataract, presence of relative afferent pupillary defect (RAPD), retinal detachment, fundal view/red reflex, other anterior and posterior segment damage and the presence of adnexal trauma) were recorded. The method of primary repair was documented. We defined a simple procedure as one necessitating corneal scleral suturing \pm anterior segment reformation. Conversely, a complex primary surgical procedure was defined as that which warranted a more invasive repair of the globe, for example, lensectomy, and vitrectomy, retinal detachment repair. Secondary surgical procedures, postoperative complications, and final visual Snellen acuity were recorded.

\section{Statistical analysis}

Firstly, exploratory factor analysis was carried out on sixteen categorical (gender, alcohol consumption, location, assault, weapon material, injury mechanism, diagnosis, RAPD, red reflex, retinal detachment, hyphaema, fundal view, wound category) and continuous (initial VA, age, number of surgical procedures) variables. Multiple regression analysis was performed using all the above-mentioned predictors and choosing a backward stepwise method. Secondly, we divided the outcome variable (final visual acuity) into four categories: VA of 0.3 Logmar or better (equivalent to $6 / 12$ ), VA between 0.3 and 1 (between $6 / 15$ and 6/60), worse than 1 (worse than 6/60), and those requiring enucleation. The relationship between predictors and final VA was further investigated using discriminant analysis. Finally, binary logistic regression was performed in order to identify the predictors associated with enucleation.

\section{Results}

Between 1 January 1998 and 1 January 2003, 115 cases of open globe injuries were identified from the computerised theatre database at the Manchester Royal Eye Hospital theatres. 107 cases notes were available for review. The remaining eight were excluded. The study group comprised 91 male and 16 female subjects. The average age of the patients was 40 years, with a median of 30 years (range: 1-89 years). Of the patients, 20 were aged 16 years or less. Average follow-up was 14.3 months, median 9.5 months (range: 1-48 months).

Three clusters of variables were identified: two clusters were related to the 'setting' (factor 1: age, alcohol consumption, assault, weapon material, and mechanisms of injury; factor 2: age, location, weapon material, and total number of operations) and the 'clinical' factors (initial VA, hyphaema, red reflex, fundal view, retinal detachment, and relative afferent pupil defect). Alcohol was documented to be a factor at presentation in 23 cases, and illicit drugs in a further three cases. Of the 107 patients, 45 suffered open globe injuries as a result of an assault. A further 25 patients presenting with a globe rupture sustained the injury in the work place, two as a result of an assault, four from high velocity injuries (eg hammer-nails), 11 from faulty or broken equipment (eg fractured Stanley knife/shattered pins), and four from falling equipment/materials. In the remaining four of this group of 25, the mechanism was unknown.

A complete classification of the mechanism of injury in the 107 cases is outlined in Tables 1-4.

Multiple regression analysis showed that the most significant predictors of final outcome were initial VA, RAPD, red reflex, mechanism of injury, and total number

Table 1 Birmingham Eye Trauma Terminology (BETT) ${ }^{9}$ classification of injury

\begin{tabular}{lc}
\hline Type of injury & Numbers $(\%) n=107$ \\
\hline Ruptures & $60(56 \%)$ \\
Lacerations penetrating & $34(32 \%)$ \\
IOFB & $10(9 \%)$ \\
Perforating & $3(3 \%)$ \\
\hline
\end{tabular}


Table 2 Type of injury classified by intent

\begin{tabular}{lc}
\hline Type of injury & Numbers (\%) $n=107$ \\
\hline Accidental & $59(55 \%)$ \\
Assault & $45(42 \%)$ \\
Falls & $8(7 \%)$ \\
Unknown & $3(3 \%)$ \\
\hline
\end{tabular}

Table 3 Place of injury

\begin{tabular}{lc}
\hline Place of injury & Numbers $(\%) n=107$ \\
\hline Work & $25(23 \%)$ \\
Home & $23(21 \%)$ \\
School & $5(5 \%)$ \\
Outdoors & $39(36 \%)$ \\
Indoors & $36(34 \%)$ \\
Recreation & $32(30 \%)$ \\
Sport & $1(1 \%)$ \\
RTA & $0(0 \%)$ \\
Unknown & $14(13 \%)$ \\
\hline
\end{tabular}

Table 4 Nature of injury

\begin{tabular}{lc}
\hline Nature of Injury & Numbers $(\%) n=107$ \\
\hline Assault with glass & $24(23 \%)$ \\
Blunt injury fist & $9(8 \%)$ \\
Fall & $8(7 \%)$ \\
BB / pellet gun & $5(5 \%)$ \\
Knife/folk & $4(4 \%)$ \\
Pencil & $4(4 \%)$ \\
Hammer on metal nail & $4(4 \%)$ \\
Metal bar & $2(2 \%)$ \\
Shattered glasses & $2(2 \%)$ \\
Golf club & $1(1 \%)$ \\
Explosion bomb & $1(1 \%)$ \\
Miscellaneous & $38(36 \%)$ \\
Unknown & $1(1 \%)$ \\
\hline
\end{tabular}

of operations. Discriminant analysis was also performed. The resulting model was able to predict $89.7 \%$ of the final VA category and was based on initial VA (the main contributor), injury mechanism (and hence, wound type), relative afferent pupil defect, fundal visibility (presence of hyphaema, fundal view, red reflex), and total number of operations. Discriminant analysis shows that the most significant predictors are initial VA, RAPD, and red reflex. This model was able to predict the final VA category in $99.9 \%$ of the cases.

Table 5 shows factors that correlated with final outcome. Injury to the eye with a sharp object (including projectile sharp objects, such as glass) was the most common mechanism of injury accounting for 71/107 $(66 \%)$ cases. Blunt mechanisms of injuries (including projectile blunt objects, such as BB gun injuries)
Table 5 Factors correlating with final visual outcome. Three patients were excluded (no follow-up data of final visual acuity)

\begin{tabular}{ccccc}
\hline Variable & \multicolumn{4}{c}{ Final visual outcome } \\
\cline { 2 - 5 } & $V A$ & $V A$ & $C F-N P L$ & $A E$ \\
& $<6 / 12$ & $6 / 15-6 / 60$ & $(n=25)$ & $(n=13)$ \\
& $(n=49)$ & $(n=17)$ & & \\
\hline
\end{tabular}

\begin{tabular}{|c|c|c|c|c|c|}
\hline \multicolumn{6}{|l|}{ Initial VA } \\
\hline$<6 / 12$ & 12 & 1 & 0 & 0 & \multirow[t]{4}{*}{$P=0.03$} \\
\hline $6 / 15-6 / 60$ & 17 & 1 & 0 & 0 & \\
\hline$>6 / 60$ & 17 & 13 & 23 & 13 & \\
\hline Unknown & 3 & 2 & 2 & 0 & \\
\hline \multicolumn{6}{|l|}{ Hyphaеma } \\
\hline None & 0 & 9 & 5 & 2 & \multirow[t]{4}{*}{$P=0.19$} \\
\hline Partial & 14 & 4 & 11 & 5 & \\
\hline Total & 2 & 3 & 9 & 6 & \\
\hline Unknown & 33 & 1 & 0 & 0 & \\
\hline \multicolumn{6}{|l|}{$R A P D$} \\
\hline $\mathrm{Y}$ & 4 & 1 & 8 & 12 & \multirow[t]{3}{*}{$P<0.001$} \\
\hline $\mathrm{N}$ & 20 & 11 & 7 & 0 & \\
\hline ND & 25 & 5 & 10 & 1 & \\
\hline \multicolumn{6}{|l|}{$\begin{array}{l}\text { Retinal } \\
\text { detachment }\end{array}$} \\
\hline Y & 2 & 2 & 11 & 3 & \multirow[t]{3}{*}{$P=0.01$} \\
\hline $\mathrm{N}$ & 45 & 15 & 14 & 10 & \\
\hline Unknown & 2 & 0 & 0 & 0 & \\
\hline \multicolumn{6}{|l|}{ Red reflex } \\
\hline $\mathrm{Y}$ & 38 & 10 & 7 & 0 & \multirow[t]{3}{*}{$P<0.001$} \\
\hline $\mathrm{N}$ & 9 & 5 & 16 & 12 & \\
\hline Unknown & 2 & 2 & 2 & 1 & \\
\hline \multicolumn{6}{|l|}{ Injury } \\
\hline Blunt & 9 & 4 & 10 & 7 & \multirow{3}{*}{$P=0.004$} \\
\hline $\begin{array}{l}\text { Sharp/ } \\
\text { projectile }\end{array}$ & 40 & 11 & 14 & 6 & \\
\hline Unknown & 0 & 2 & 1 & 0 & \\
\hline \multicolumn{6}{|l|}{ Lid laceration ${ }^{\mathrm{a}}$} \\
\hline Y & 11 & 6 & 5 & 8 & \multirow[t]{2}{*}{$P=0.030$} \\
\hline $\mathrm{N}$ & 38 & 11 & 20 & 5 & \\
\hline
\end{tabular}

BETT

$\begin{array}{lrrrrr}\text { category }^{\text {a }} \text { ( } & & & & & \\ 1 & 21 & 4 & 3 & 0 & P=0.896 \\ 2 & 21 & 10 & 15 & 9 & \\ 3 & 6 & 3 & 4 & 3 & \\ 4 & 1 & 0 & 2 & 1 & \\ \text { Unknown } & 0 & 0 & 1 & 0 & \end{array}$

Number of procedures

$\begin{array}{lrrrrr}1 & 24 & 8 & 6 & 1 & P=0.001 \\ 2 \text { or more } & 12 & 3 & 14 & 9 & \end{array}$

$\mathrm{ND}=$ not documented. $\mathrm{AE}=$ artificial eye.

${ }^{\mathrm{a}}$ Not correlated.

accounted for another $30 / 107(28 \%)$ cases. In six $(6 \%)$ cases the cause of injury was unknown. Glass was the major cause of injury from sharp objects, accounting for 
$31 / 71$ (44\%) cases in this group. Darts, knives, forks, metal pins, slate, wire, pencils, and screwdrivers accounted for the remaining 40/71 (56\%) cases. Similarly, in the blunt injury group, the most common mechanism of injury was with fists $(9 / 30(30 \%)$ cases). Falls and contact with other objects accounted for the remainder of cases. Those with sharp injuries had a significantly better final visual prognosis than those suffering blunt open globe injuries $(P=0.004)$, with $40 / 71(56 \%)$ cases of sharp injuries achieving $6 / 12$ or better compared to $9 / 30$ (30\%) cases with blunt injuries achieving a similar level of visual acuity.

Air gun injuries accounted for five cases in our series. The average initial visual acuity at presentation was hand movements. Four patients suffered penetrating eye injuries and one patient suffered a perforating injury. Two patients achieved Snellen acuity of $6 / 12$ or better following two procedures and three required enucleation within 2 weeks. Injuries with air guns were significantly associated with a poor visual outcome $(P=0.03$, odds ratio $(\mathrm{OR})=9.3,95 \%$ CI $1.4-62.8)$.

Initial good visual acuity (6/60 or better) was associated with an excellent visual outcome $(6 / 12$ or better) in $28 / 30(93 \%)$ cases $(P<0.001)$. A final visual acuity of $6 / 60$ or better was achieved in $100 \%$ of these cases. If the presenting visual acuity was worse than 6/60 however, as was the case in 66 patients, the eventual visual outcome was variable. In total, 17/66 (26\%) achieved $6 / 12$ or better, $13 / 66(20 \%)$ achieved between 6/15 and 6/60, 23/66 (35\%) achieved CF to NPL, and a further 13/66 (19\%) progressed to enucleation. In patients who presented with a good visual acuity (6/60 or better) none underwent enucleation, compared to those with a Snellen visual acuity of $6 / 60$ or worse, where 13/66 (20\%) of patients were eventually enucleated. This difference in outcome is statistically significant $(P=0.009, \mathrm{OR}=14.05)$.

Several mechanisms were related to the eventual need for enucleation. The rate of enucleation in our series of 107 open globe injuries was 13/107 (12\%) patients. All patients underwent primary repair. The average time from injury to enucleation was 25 weeks (range: 1 day-24 months). Statistically significant risk factors present on initial presentation associated with eventual enucleation include a blunt mechanism of injury $(P=0.0128$, $\mathrm{OR}=7.38)$, the absence of a red reflex $(P<0.001$, $\mathrm{OR}=0.03)$, the presence of a lid laceration $(P=0.01$, $\mathrm{OR}=5.88)$, and an RAPD $(P<0.001$, OR =52.04). When analysing all these predictors together using binary logistic regression however, it emerges that the presence of relative afferent pupil defect is the strongest predictor. Other common signs at presentation in patients included the presence of a hyphaema in $91 / 107(85 \%)$ cases, uveal prolapse/loss of uveal tissue in 91/107 (85\%), lens abnormality in 66/107 (62\%), enophthalmos in 66/107 $(62 \%)$, and an orbital fracture in $41 / 107$ (38\%) cases.

Results of the examination of an RAPD were recorded preoperatively in 67/107 (63\%) cases. In 39/67 (58\%), an RAPD was absent, but present in the remaining 28/67 (42\%). If present, an RAPD was strongly associated with a poor outcome $(P<0.001)$. Snellen visual acuity in patients presenting with an RAPD varied. Final visual acuity of $6 / 12$ or better was achieved in $4 / 28(16 \%), 6 / 15$ to $6 / 60$ in $1 / 28(4 \%)$, and counting fingers to hand movements in 4/28 (16\%). In a further 4/28 (16\%) optimal visual function consisted of light perception. A final 9/28 (32\%) required enucleation of the traumatised eye.

In all, 10 patients presented following injuries that resulted in intraocular foreign bodies (IOFB). In three cases, metal on metal was the causative factor. Another two cases resulted from malfunctioning tools at work. A further patient suffered an assault with a glass object, which shattered resulting in an IOFB. Presenting VA was $6 / 12$ or better in two cases, 6/60 or better in two cases, $\mathrm{CF}$ to HM in four cases, and PL in two cases. In the latter six patients, four had documented RAPD at presentation. Eight eyes underwent primary vitrectomy for removal of the posterior segment IOFB. The remaining two eyes underwent anterior chamber removal of the IOFB. Five eyes recovered to $6 / 12$ or better, two further eyes recovered to between $6 / 15$ and $6 / 60$. Only one eye required enucleation and the remaining two eyes achieved only NPL and HM, respectively.

In the series there were three cases of endophthalmitis. All three were as a result of injuries from sharp glass objects. Although treated aggressively, visual outcome was poor, with two achieving PL and 1 NPL after longterm follow-up. We did not find any cases of sympathetic ophthalmia during follow-up.

\section{Discussion}

Open globe injuries are a common and often preventable cause of permanent visual impairment and visual loss. The standard practice of ophthalmologists worldwide in these cases has been to undertake a primary surgical repair to restore the structural integrity of the globe at the earliest opportunity regardless of the extent of the injury and the presenting visual acuity. Only subsequent to the initial repair is enucleation considered. Certain mechanisms of injuries, however, carry a dismal prognosis regardless of how quickly and aggressively they are treated. Failure to primarily enucleate a severely traumatised globe with no visual potential can have a deleterious effect on the ability of allied specialties to repair associated maxillofacial injuries for fear of damaging the repaired globe. Further, secondary 
enucleation requires additional general anaesthesia, presents a higher risk of implant exposure and extrusion, and further compounds the already significant psychological effect of poor cosmesis.

In most population-based studies to date, ${ }^{7,10-14}$ there is a strong preponderance for open globe injuries to affect males, which we have confirmed. This may reflect the more aggressive characteristics of male behaviour and to a lesser extent the involvement of men in higher risk working activities. The use of alcohol and illegal drugs is difficult to quantify, as our series did not allow formal testing due to its retrospective nature. Nevertheless, 23/107 (21\%) patients admitted to alcohol consumption at presentation and a further 3/107 (3\%) admitted to the use of illicit drugs. This is likely to be a gross under representation. In their series of open globe injuries, Groessl et $a l,{ }^{10}$ Dannenberg et $a l_{,}^{1}$ and Smith et $a l^{11}$ described a rate of alcohol/drug usage in this setting of $73 \%, 52 \%$, and $35 \%$, respectively, suggesting that this indirect aetiological factor may have a profound effect on the incidence of open globe injuries.

In our series, several factors correlated with the final VA. Initial VA has been shown in many studies to be a key factor in predicting the rate of enucleation and, thus, poor visual outcome. ${ }^{10,12,15,16}$ We confirm that a visual acuity of worse than $6 / 60$ has a significantly inferior outcome than visual acuities of $6 / 60$ or better $(P=0.03)$, and is, therefore, a strong predictor of eventual enucleation. Pieramici et $a l^{15}$ described a significantly reduced rate of enucleation if the presenting visual acuity was $6 / 60$ or better, whereas $34 \%$ of those with a presenting visual acuity of worse than 6/60 underwent eventual enucleation. Groessl et $a l^{10}$ found that an initial visual acuity of HM or better was correlated with a good outcome. In our series, a good VA on presentation correlated with good final VA. Nevertheless, some patients with a good initial VA may undergo eventual enucleation while others with poor initial VA may not require enucleation.

Injury by sharp objects is among the most common mechanism of injury. Glass accounts for the majority of such injuries. In our series, sharp injuries accounted for $71 / 107(66 \%)$ cases, $31 / 71(44 \%)$ with broken glass as an aetiological factor. This is somewhat reassuring in that sharp injuries are correlated with a more favourable visual outcome when compared to blunt mechanisms. ${ }^{10,15,17}$ We confirm this view with a statistically significant improved visual outcome in patients suffering sharp injuries compared to blunt injuries $(P=0.004)$.

Of the clinical signs at presentation, the presence of an RAPD was highly significant in predicting outcome. If present, the outcome was significantly worse than if not present $(P<0.001)$. In all, $12 / 28$ eyes $(48 \%)$ proceeded to eventual enucleation if an RAPD was present at initial examination compared to no enucleations if an RAPD was not present. This supports the view of Pieramici et $a l^{15}$ that if an RAPD was present visual outcome was significantly worse $(P<0.0001)$. In their series, $55 \%$ of eyes were enucleated if an RAPD was documented at presentation, compared to $7 \%$ in the absence of an RAPD. Similarly, the initial observation of no red reflex, the presence of a retinal detachment, and occurrence of a lid laceration were indicative of a poor eventual visual outcome.

The number of surgical procedures performed appears to correlate with outcome. If an eye is so badly damaged that visual potential is limited, performing several procedures will not change the outcome. However, an eye with good visual potential after open globe injury may require up to two procedures to achieve optimal VA. Similarly, this did not change depending on the mechanism of injury. Patients with blunt injuries underwent an average 1.75 operations, while sharp injuries patients underwent 1.59 operations $(P=0.385)$. Injuries requiring a single initial procedure to restore the structural integrity of the globe faired better than those requiring more than one procedure. This is not unexpected as eyes with less severe trauma require fewer procedures. Williams et $a l^{16}$ reported that the number of separate procedures had a predictive value on outcome. This was supported by Pieramici et al. ${ }^{15}$ Groessl et al ${ }^{10}$ described a good visual outcome in $90 \%$ of cases if only a single procedure was performed. Those who required more than one surgical procedure did not fare as well.

In our series, we found a higher rate of enucleation and worse visual outcome in those with injuries associated with lid lacerations and adnexal trauma, often as a result of blunt injuries. This view is supported by Hatton et al. ${ }^{18}$ This is not such a surprising outcome as blunt injuries, due to assaults and falls, present with complex corneo-scleral ruptures with posteriorly located wounds. In contrast, sharp and projectile injuries often result in corneal wounds that often present less of a dilemma in performing primary repair. The wounds are clean cut and less ragged and posterior segment involvement is uncommon. These factors aid in maintaining globe integrity and optimisation of vision.

\section{Conclusion}

Open globe injuries present an ophthalmologist with management dilemmas with many unresolved controversies. The visual prognosis at presentation is often difficult to assess leading to the vast majority of injuries progressing to primary repair. Multiple 
intraocular surgical procedures may be performed on such eyes in an attempt to salvage some useful vision, but increase the risk of sympathetic ophthalmitis. In this retrospective review, we have shown several factors that may aid the clinician in deciding on the prognostic value of primary repair. Blunt injuries associated with adnexal trauma, presenting initial visual acuity of worse than $6 / 60$, the presence of an RAPD, the absence of a red reflex, and the presence of a retinal detachment are associated with a significantly higher rate of enucleation. It is reassuring, however, that the majority of injuries are secondary to sharp objects and these have a better prognosis.

Failure to enucleate a severely traumatised globe with no visual prognosis may severely restrict the ability of allied specialties in their quest to repair associated maxillofacial injuries for fear of damaging the repaired globe. This may further severely compromise the patient's cosmetic rehabilitation, as the results of secondary reconstruction are far inferior to those of primary reconstruction. Furthermore, secondary enucleation in this setting is associated with a higher rate of implant extrusion/exposure and a longer rehabilitative period, further compounding the psychological effects of the trauma. In certain situations, primary enucleation should be considered the treatment of choice. For example, it may be inappropriate in an elderly patient to undertake a protracted and complicated primary repair of a severely traumatised globe under general anaesthesia when an enucleation or evisceration under local anaesthesia with sedation may be in their best interests.

\section{References}

1 Dannenberg AL, Parver LM, Fowler CJ. Penetrating eye injuries related to assault. The National Eye Trauma System Register. Arch Ophthalmol 1992; 110: 849-852.

2 Dannenberg AL, Parver LM, Brechner RJ, Khoo L. Penetrating eye injuries in the workplace. The National Eye Trauma System Registry. Arch Ophthalmol 1992; 110: 843-848.
3 Tielsch JM, Parver L, Shankar B. Time trends in the incidence of hospitalised trauma. Arch Ophthalmol 1989; 107: 519-523.

4 Gilbert CM, Soong HK, Hirst LW. A two-year prospective study of penetrating ocular trauma at the Wilmer Ophthalmological Institute. Ann Ophthalmol 1987; 19: 104-106.

5 Liggett PE, Pince KJ, Barlow W, Ragen M, Ryan SJ. Ocular trauma in an urban population. Review of 1132 cases. Ophthalmology 1990; 97: 581-584.

6 Desai P, MacEwen CJ, Baines P, Minassian DC. Incidence of cases of ocular trauma admitted to hospital and incidence of blinding outcome. Br J Ophthalmol 1996; 80: 592-596.

7 Fong LP. Eye injuries in Victoria, Australia. Med J Aust 1995; 162: 64-68.

8 deBustros S, Michels RG, Glaser BM. Evolving concepts in the management of posterior segment penetrating ocular injuries. Retina (Suppl) 1990; 10: S72-5.

9 Kuhn F, Morris F, Witherspoon CD, Mester V. The Birmingham Eye Trauma Terminology system (BETT). J Fr Ophthalmol 2004; 27: 206-210.

10 Groessl S, Nanda SK, Mieler WF. Assault-related penetrating ocular injury. Am J Ophthalmol 1993; 116: 26-33.

11 Smith D, Wrenn K, Stack LB. The epidemiology and diagnosis of penetrating eye injuries. Acad Emerg Med 2002; 9: 209-213.

12 Esmaeli B, Elner SG, Schork MA, Elner VM. Visual outcome and ocular survival after penetrating trauma. A clinicopathologic study. Ophthalmology 1995; 102: 393-400.

13 Wong TY, Tielsch JM. A population based study on the incidence of severe ocular trauma in Singapore. Am J Ophthalmol 1999; 128: 345-351.

14 Klopfer J, Tielsch JM, Vitale S, See LC, Canner JK. Ocular trauma in the United States. Eye injuries resulting in hospitalization, 1984 through 1987. Arch Ophthalmol 1992; 110: 838-842.

15 Pieramici DJ, MacCumber MW, Humayun MU, Marsh MJ, de Juan Jr E. Open globe injuries. Update on types of injuries and visual results. Ophthalmology 1996; 103: 1798-1803.

16 Williams DF, Mieler WF, Abrams GW, Lewis H. Results and prognostic factors in penetrating ocular injuries with retained intraocular foreign bodies. Ophthalmology 1988; 95: 911-916.

17 Dunn ES, Jaeger EA, Jeffers JB, Freitag SK. The epidemiology of ruptured globes. Ann Ophthalmol 1992; 24: 405-410.

18 Hatton MP, Thakkar MM, Ray S. Orbital and adnexal trauma associated with open globe injuries. Ophthalmol Plast Reconstr Surg 2002; 18: 458-461. 